\title{
Investigation of factors affecting ethical decision-making process of community pharmacists in professional life
}

\author{
Miray ARSLAN 1 *, Nilay TARHAN ${ }^{2}$, Selin KALENDER ${ }^{3}$, Sevgi ŞAR ${ }^{4}$ \\ 1 Department of Pharmacy Management, Faculty of Pharmacy, Van Yüzüncü Yıl University, Van, Turkey. \\ 2 Department of Pharmacy Management, Faculty of Pharmacy, İzmir Katip Çelebi University, İzmir, Turkey. \\ 3 Department of Information Systems, Turkish Medicines and Medical Devices Agency (TMMDA) Ankara, Turkey \\ 4 Department of Pharmacy Management, Faculty of Pharmacy, Ankara University, Ankara, Turkey \\ * Corresponding Author. E-mail: eczmirayarslan@gmail.com (M.A.); Tel. +90-444 50 65/21177; ORCID No: 0000- \\ 0003-2786-4610.
}

Received: 28 February 2018 / Revised: 3 May 2018 / Accepted: 9 May 2018

\begin{abstract}
Ethics is defined as questioning the practice of moral standards and whether moral standards are logical or not. The struggle to determine the rules that should be followed by those who demonstrate activities in a particular field and the ethical principles of practice that is specific to it reveal the concept of professional ethics. The principles of professional ethics, is very important for a profession, have become more attractive in the field of pharmacy as it is in every field. In this regard, pharmacists need to consider the professional ethical principles in relation to their patients, colleagues or other employees. This study aims to determine the perceptions of community pharmacists about professional ethics through a sample case can be encountered in a pharmacy. In this context, the prepared questionnaire, consists of 24 questions, was conducted to randomly select 150 community pharmacists face to face in Ankara. The obtained data were statistically analyzed via SPSS 18.0 package program. Firstly, descriptive statistical analyzes were performed and followed by exploratory factor analysis (EFA). As a result of EFA four factors are obtained as: "financial and legal pressure", "patient benefit", "colleague pressure", and "patient confidence". These factors explained 68.033\% of the total variance. $t$-test and ANOVA were used to determine the effects of demographics of pharmacists on the factors. Obtained results are of great importance in determining the perceptions of pharmacists regarding professional ethics. Knowing the factors affecting the pharmacist's behavior in accordance with the professional ethics will shed light on community pharmacy practices.
\end{abstract}

KEYWORDS: Community pharmacists; ethics; exploratory factor analysis; professional ethics.

\section{INTRODUCTION}

Ethics is defined as questioning the practice of moral standards and whether moral standards are logical or not. As a sub-branch of ethics, professional ethics can be defined as a collection of principles and rules based on beliefs about what is right and wrong about a professional behavior [1,2]. The aim of professional ethics is to direct and manage employees in businesses by behavioral rules and principles, which helps to get public confidence, during production and service processes [2,3]. Community pharmacists should pay attention to the balance between business and healthcare practice related issues in their professional life. Therefore, providing public confidence is very essential for the prestige of pharmacy profession. In this regard, the principles of professional ethics that is very important for a profession have taken more attention in the field of pharmacy as it is in every field.

Community pharmacists are encountering with different ethical issues in their professional life. When medication-related adviser role of community pharmacists are taken into consideration, it can be seen that pharmacists are trustable consultants for over the counter drugs (OTCs) [4-7]. Additionally, in the literature, it is pointed out that some ethical issues may occur at the presenting of OTC products [8,9]. In this regard, this study aims to determine the perceptions of community pharmacists about professional ethics through a sample case including an ethical problem about presenting an OTC product. Accordingly, a questionnaire related to the case was applied to investigate the factors affecting ethical decision-making process of community pharmacists. 


\section{RESULTS}

The demographic characteristics of the participants $(n=150)$ are given in Table 1.

Table 1. Characteristics of the participants

\begin{tabular}{lc}
\hline Characteristics of the participants & Frequency (\%) \\
\hline Gender & \\
Female & 49.3 \\
Male & 50.7 \\
\hline Age & \\
$\quad<30$ & 20.7 \\
$30-40$ & 25.3 \\
$40-50$ & 25.3 \\
$>50$ & 28.7 \\
\hline Graduated faculty & \\
Ankara Uni. Faculty of Pharmacy & 36.7 \\
Gazi Uni. Faculty of Pharmacy & 21.3 \\
Hacettepe Uni. Faculty of Pharmacy & 23.3 \\
Others & 18.7 \\
\hline Education level & \\
Bachelor & 82.7 \\
Master & 14.7 \\
Doctorate & 2.7 \\
\hline Working year & \\
<10 years & 35.3 \\
10-20 years & 28.0 \\
20-30 years & 23.3 \\
>30 years & 13.3 \\
\hline
\end{tabular}

A sample case related with OTCs were given in the measurement tool and firstly a question "Do you think the pharmacist should sell this OTC product?" was asked to reveal the opinions of pharmacists about what kind of preference should be made when such a situation is occurred. $30.7 \%$ of the participants answered this question as "Yes", 59.3\% of them answered as "No", and 10\% of them answered as "Undecided".

Subsequently, exploratory factor analysis (EFA) was applied. Four of the measurement items with low factor loadings (less than 0.50) were removed. The other 14 items were included under four factors. KaiserMeyer-Olkin (KMO) measure was calculated as 0.707 , which was verifying the sampling adequacy. Determined four factors explained $68.033 \%$ of the total variance. These factors were labeled as patient confidence (PC), financial and legal pressure (FLP), colleague pressure (CP), and patient benefit (PB). Results of EFA is given in Table 2.

Two-sample independent t-test was used for analyzing if the gender or participating in a vocational training have a significant effect at $5 \%$ significance level on factors or not. There is no significant difference found between gender groups, and participating in a vocational training has no significant effect on factors. One-way variance analysis (ANOVA) is used for investigating if there is any significant differences between age groups, between educational levels, between faculties graduated from, and between working year groups within the factors or not. Statistically significant differences were not found between these groups within the factors at $5 \%$ significance level (Table 3). Lastly effect of the answers of the participants to "Do you think the pharmacist should sell this OTC product?" on the factors was examined by ANOVA at $5 \%$ significance level. Statistically significant difference found within PC, FLP, and PB factors (Table 3).

Because of variances are homogeneous, Tukey test is performed to find which groups are different from another. Mean values for the items of PC factor were found higher for the pharmacists who think that the specified OTC product should not be sold and those who are undecided than pharmacists who think they can sell. Mean values for the items of FLP factor were found higher for the pharmacists who think that the specified OTC product can be sold and those who are undecided than the pharmacists who think they should not sell. Additionally, mean values for the items of $\mathrm{PB}$ factor were found higher for the pharmacists who think that the specified OTC product can be sold than who think they should not sell. 
Table 2. Results of exploratory factor analysis

\begin{tabular}{|c|c|c|c|c|c|}
\hline Factors and items & $\begin{array}{c}\text { Mean } \\
(\bar{x})\end{array}$ & PC & FLP & PB & $\mathbf{C P}$ \\
\hline $\begin{array}{l}\text { Patient Confidence (PC) / Cronbach's alfa }=\mathbf{0 . 8 0 0} \\
\text { Having different options that can be offered to patients. } \\
\text { Do not want to lose patient's respect. } \\
\text { Do not want to disappoint the patient. } \\
\text { The fact that the patient's pain can be reduced with a more affordable product. } \\
\text { Do not want to lose patient's confidence. }\end{array}$ & $\begin{array}{l}3.687 \\
4.327 \\
4.080 \\
3.800 \\
4.267\end{array}$ & $\begin{array}{l}0.806 \\
0.804 \\
0.752 \\
0.748 \\
0.561\end{array}$ & & & \\
\hline $\begin{array}{l}\text { Financial and Legal Pressure (FLP) / Cronbach's alfa }=0.804 \\
\text { The pharmacist is under great financial pressure. } \\
\text { There is no legal offense in selling OTC products. } \\
\text { It is also necessary to generate financial income in the sustainability of the pharmacy. } \\
\text { The Ministry of Health does not have any warning for that product. }\end{array}$ & $\begin{array}{l}2.807 \\
3.133 \\
3.213 \\
3.327\end{array}$ & & $\begin{array}{l}0.811 \\
0.802 \\
0.719 \\
0.664\end{array}$ & & \\
\hline $\begin{array}{l}\text { Patient Benefit }(\mathbf{P B}) / \text { Cronbach's alfa }=0.802 \\
\text { Need to offer the client symptom relief to retain her loyalty to the pharmacy. } \\
\text { Meeting the needs of the patient. } \\
\text { Providing symptom relief to the client will help her feel less pain. }\end{array}$ & $\begin{array}{l}3.667 \\
4.007 \\
3.720\end{array}$ & & & $\begin{array}{l}0.829 \\
0.784 \\
0.755\end{array}$ & \\
\hline $\begin{array}{l}\text { Colleague Pressure }(\mathbf{C P}) \text { / Cronbach's alfa }=\mathbf{0 . 7 9 3} \\
\text { Other pharmacists would approve such a recommendation. } \\
\text { This situation is fair for other pharmacists, too. }\end{array}$ & $\begin{array}{l}2.167 \\
2.513\end{array}$ & & & & $\begin{array}{l}0.860 \\
0.835\end{array}$ \\
\hline Variance Explained (\%) & & 20.020 & 19.740 & 15.247 & 13.026 \\
\hline Cumulative Variance Explained (\%) & & 20.020 & 39.761 & 55.007 & 68.033 \\
\hline
\end{tabular}

Table 3. Two sample independent t-test and ANOVA results

\begin{tabular}{|c|c|c|c|c|c|c|c|c|c|c|c|c|}
\hline & \multicolumn{2}{|c|}{ Gender } & \multicolumn{2}{|c|}{$\begin{array}{c}\text { Educational } \\
\text { level }\end{array}$} & \multicolumn{2}{|c|}{ Working Year } & \multicolumn{2}{|c|}{$\begin{array}{l}\text { Graduated } \\
\text { Faculties }\end{array}$} & \multicolumn{2}{|c|}{$\begin{array}{c}\text { Participating } \\
\text { in vocational } \\
\text { training }\end{array}$} & \multicolumn{2}{|c|}{$\begin{array}{l}\text { Do you think } \\
\text { the pharmacist } \\
\text { should sell this } \\
\text { OTC product? }\end{array}$} \\
\hline & $t$ & Sig. & $F$ & Sig. & $\mathbf{F}$ & Sig. & $\mathbf{F}$ & Sig. & $t$ & Sig. & $\mathbf{F}$ & Sig. \\
\hline $\begin{array}{l}\text { Factors } \\
\text { PC }\end{array}$ & 0544 & 0587 & 2009 & 0113 & 1768 & 0156 & O 995 & 0397 & O 381 & 0704 & 13946 & $0000 *$ \\
\hline FLP & -0.747 & 0.456 & 0.052 & 0.950 & 1.222 & 0.304 & 2.111 & 0.101 & 0.073 & 0.942 & 16.992 & $0.000^{*}$ \\
\hline PB & 0.788 & 0.432 & 0.369 & 0692 & 1.001 & 0.394 & 0.101 & 0.959 & -0.205 & 0.837 & 0.224 & 0.799 \\
\hline $\mathrm{CP}$ & -1.267 & 0.207 & 1.935 & 0.148 & 2.106 & 0.149 & 1.323 & 0.269 & -0.324 & 0.746 & 5.801 & $0.004^{*}$ \\
\hline
\end{tabular}

* The mean difference is significant at the 0.05 level.

\section{DISCUSSION}

As a result of this study, the factors that are effective in the decision-making process of pharmacists when faced with a case that should be evaluated ethically were tried to be determined. In pharmacy practice, professional ethics are often encountered equally to the basic medical ethics listed as beneficence, nonmaleficence, autonomy, and justice [10]. In this context, it is expected that pharmacists will continue their services by integrating professional ethical principles and basic medical ethics together and adhering these principles. In the literature, the number of studies on perceptions of pharmacists towards professional ethics is limited and it is seen that the principles of professional ethics and basic principles of pharmacy ethics are evaluated as a whole in these studies. Studies about professional ethics in the literature generally were conducted by presenting a sample case such this study, hence it is thought that more subjective information can be obtained from the participants by this way [11,12]. Crnjanski et al. (2016) developed an Ethical Issue Scale for Community Pharmacy Setting (EISP), which consists 19 statements about ethical cases to determine the difficulty and frequency of ethical issues faced in pharmacy practice for the pharmacists [12]. In the present study, an ethical case prepared by Chaar (2009) was used [10]. This case is about a pharmacist who has financial difficulties and presenting a product that has lack of evidence about its efficacy to an elderly woman (Please see Appendix A for details). Chaar (2009) presented 3 different ethical cases and 12 questions for each case. As a result, three factors were found as patient rights, rules and regulations, and business orientation 
[10]. In the present study, because of choosing only one case and accordingly decreasing the number of the questions to increase the rate of participation to the survey, the number of factors were changed. However, items within the factors were parallel to the original study. It is considered that nearly $60 \%$ of the participants will not sell this OTC product when they will face such a case. The four main factors that influence these decisions of participants were decided as patient benefit, patient trust, financial and legal pressures, and colleague pressure.

In the development of professions, professional organizations have major tasks. Following the undergraduate education, it is aimed to make the progress of the members of professions continuous with vocational training. This also applies to professional ethics. Therefore, professional organizations play very serious roles in the formation of professional ethics in a profession and in the regulation of professional ethics. In this study, the effects of education levels, graduated faculty and vocational training on ethical decisionmaking processes were also discussed. However, it was found that these three educational factors did not make any significant difference in the factors. It is seen that approximately $47 \%$ of the participants have participated in vocational training related to the professional ethics. However, participating in a vocational training program has no significant effect on the answers given for the "Do you think the pharmacist should sell this OTC product?" question. This result can be regarded as a sign that the vocational training related to professional ethics is inadequate, also it brings to mind the question of whether the ethics can be taught or not. There are different opinions in the literature about ethics, is a teachable concept or not. While some experts think that ethics can be taught, some think that tools that can help to teach ethical behavior can be taught, but ethics cannot [13]. In this context, it is important that ethics and professional ethics are included in pharmacy faculty programs and in vocational training programs, but it is considered that education contents should be developed in order to that these trainees could make a difference.

Sharif et al. (2011) identified working experience and age are effective elements in ethical decisions of pharmacists [14]. Contrarily, in this study, working years and age groups had no significant effects on the factors. Although Latif (2004) stated that women are more sensitive to ethical issues than men, Sharif et al. (2011) found gender not effective. In this study, gender groups did not make any significant differences in the factors $[14,15]$.

In many social and behavioral studies, the colleague pressure is also discussed under the social pressure $[16,17]$. Similarly, in this study, one of the effective factors in ethical decision-making process of pharmacists was found as colleague pressure. Therefore, it was thought that support of colleagues is an important issue for pharmacists as well as for many other professional groups. Yildiz (2010) stated one of the most important factors that directed the members of the profession towards unethical behaviors was the colleagues [18]. In contrast, the present study has been revealed that this situation is different in terms of pharmacy profession. When the findings obtained in this study were examined, it was determined that pharmacists rated the importance of the expressions under the colleague pressure as 2 (with possible max. 5). This result is regarded as an indication that pharmacists will not prefer such an unethical behavior, even if their colleagues will support them.

As a result of ANOVA, mean values for the items of patient confidence factor were found higher for the pharmacists who think that the specified OTC product should not be sold and those who are undecided than the pharmacists who think they can. When the items in this factor were investigated, it is seen that pharmacists did not approve selling a product that has lack of evidence about its efficacy especially in accordance with beneficence principle. This situation can be supported by basic professional ethics principles such as honesty, truthfulness, responsibility, and openness. Besides, the answers to the items under this factor are generally above 3.80. This is an indicator of that pharmacists are striving to gain patient confidence by giving priority to patient satisfaction and benefit when facing an ethical case.

Ylldiz (2010) found out economic reasons and inadequate laws forced individuals to behave unethically [18]. Al-Arifi (2014) stated commercial concerns and financial conditions are influential in selling OTC products by pharmacists, and sometimes this situation may cause some ethical problems in community pharmacies [8]. Rodrigues and Juricic (2017) pointed out the reasons of frequently encountered ethical problems in community pharmacies as dispensing prescribed medicine without a prescription or with an incorrect prescription, dispensing controlled drugs or emergency hormonal contraception, refusing to dispense medicines, lack of professional autonomy, and financial pressure [9]. In this study, it can be seen that the averages of items under the financial and legal pressure factor generally changed between 2.50 to 3.50 . It is known that community pharmacists in our country suffer from some financial and economic difficulties [19]. Nevertheless, the results supported that pharmacists value ethical behaviors more than financial issues. The reason for higher answer 
averages of pharmacists who think that the specified OTC product can be sold and those who are undecided is considered a sign of having some economic and financial problems when practicing their professions. At this point, pharmacists should give the priority to patient benefit instead of economic issues and act according to beneficence principle.

As a result of the analysis, it is found that mean values for the items of PB factor were found higher for the pharmacists who think that the specified OTC product can be sold than who think should not be sold. At this point, the pharmacists need to take into account the principle of beneficence as well as the principle of non-maleficence. It is thought that pharmacists should avoid selling a product that has lack of evidence about its efficacy within the framework of professional competence and responsibility principles, even to ensure patient loyalty. Additionally, means of the items in this factor were above 3.60, this shows that pharmacists give priority to the benefit of the patients.

\section{CONCLUSION}

The results obtained in this study are of great importance in determining the perceptions of pharmacists on professional ethics. In this study, offering a product that has lack of evidence about its efficacy, which is also more expensive, to a patient has been addressed by the presented case. According to the case, it is thought that selling this product in terms of professional ethics is not correct. In this study, it is seen that the decision making process of pharmacists can be evaluated with four sub-dimensions as legal and financial pressure, colleague pressure, patient benefit, and patient confidence. It is thought that these four basic sub-dimensions will shed light on the future work in the field of pharmacy.

The number of studies addressing the community pharmacists' perceptions about professional ethics in Turkey is very limited. To the best of the authors' knowledge, this is the first study that takes community pharmacists perceptions towards ethical decision-making in their professional life in Turkey. In this context, this study is also very important in terms of establishing awareness about professional ethics in community pharmacists.

\section{MATERIALS AND METHODS}

The measurement tool applied in this study was adapted from the professional ethics in pharmacy test prepared by Chaar (2009). 6 items of the tool for determining demographical characteristics, and 18 items, with 5 points Likert scale (1: not important to 5 : the most important), for determining pharmacists' perceptions about professional ethics according to given case. The measurement tool and the case were translated in Turkish and an expert made the language control. The measurement tool was approved by the Ankara University Ethical Committee with the Permit Number 5/87.

The population of this study consists of nearly 2000 community pharmacists in Ankara [20]. The sample size of this study was calculated by the acceptable error level method as 92; on 0.10 significance level, $t=1.96$, $\mathrm{d}$ (sensitivity) $=0.05$, and $\mathrm{p}$ and $\mathrm{q}$ values are 0.5 . In this context, the measurement tool was conducted to randomly select 150 community pharmacists face to face in Ankara. The obtained data were statistically analyzed via SPSS 18.0 package program. Firstly, descriptive statistical analyzes were performed, then exploratory factor analysis (EFA) with varimax rotation were done. In addition, t-test and ANOVA tests were used to determine the effects of demographics such as gender, age, education, working years etc. of pharmacists on the factors.

Acknowledgements: Authors want to thank community pharmacists participated in the study.

Author contributions: Author contributions: Concept - M.A., N.T.; Design - M.A., N.T.; Supervision - S.Ş.; Resource M.A., N.T., S.K., S.Ş.; Materials -.; Data Collection and/or Processing - S.K., M.A., N.T.; Analysis and/or Interpretation - M.A., N.T.; Literature Search - M.A., S.K.; Writing - M.A., N.T., S.K..; Critical Reviews - M.A., N.T., S.K., S.Ş.

Conflict of interest statement: The authors declared no conflict of interest.

\section{REFERENCES}

[1] Selimoğlu SK. Muhasebede Meslek Ahlakı (Etik) Yaklaşımı, III. Türkiye Muhasebe Denetim Sempozyumu Bildiri Kitabı. İstanbul: İSMMMO Yay. No:20, 30 Nisan- May1s, 1997, pp.145-46.

[2] Kutlu HA. Ethical Dilemmas of Professional Accountants: A Research (article in Turkish with an abstract in English). Ankara Üniversitesi SBF Dergisi. 2008; 63(2): 143-170. [CrossRef] 
[3] Smith LM, Smith KT. Accounting Information Systems, Houston TX: Dame Publication Inc., 1987.

[4] Welna EM, Hadsall RS, Schommer JC. Pharmacists' personal use, professional practice behaviors, and perceptions regarding herbal and other natural products, J Am Pharm Assoc. 2003; 43(5): 602-611.

[5] Donohue JM, Huskamp HA, Wilson IB, Weissman J. Whom do older adults trust most to provide information about prescription drugs? Am J Geriatr Pharmacother. 2009; 7(2): 105-116.

[6] Simmons-Yon A, Roth MT, Kavalieratos MVu, Weinberger DM, Rao JK. Understanding pharmacists' experiences with advice-giving in the community pharmacy setting: a focus group study, Patient Educ Couns. 2012; 89(3): 476483.

[7] Tarhan N, Arslan M, Şar S. A structural equation model for pharmacy students' acquiring knowledgebased behavior towards complementary and alternative medicine. Eur J Integ Med. 2017; 16: 54-60. [CrossRef]

[8] Al-Arifi MN. Community pharmacist perception and attitude toward ethical issues at community pharmacy setting in central Saudi Arabia. Saudi Pharm J. 2014; 22(4): 315-325. [CrossRef]

[9] Rodríguez JV, Juricic Z. Perceptions and attitudes of community pharmacists toward professional ethics and ethical dilemmas in the workplace. Res Social Adm Pharm. 2018;14(5):441-450. [CrossRef]

[10] Chaar BB. Professional ethics in pharmacy practice: developing a psychiatric measure of moral reasoning. Pharm World Sci. 2009; 31(5): 439-49. [CrossRef]

[11] Wingfield J, Bissell P, Anderson C. The scope of pharmacy ethics-an evaluation of the international research literature, 1990-2002. Soc Sci Med. 2004; 58(12): 2383-96. [CrossRef]

[12] Crnjanski T, Krajnovic D, Tadic I, Stojkov S, Savic M. An Ethical Issue Scale for Community Pharmacy Setting (EISP): Development and Validation. Sci Eng Ethics. 2016; 22(2): 497-508. [CrossRef]

[13] Ryan TG, Bisson J. Can Ethics Be Taught? Int J Bus Soc Sci. 2011; 2(12): 44-52.

[14] Sharif PS, Javadi M, Asghari F. Pharmacy ethics: evaluation pharmacists' ethical attitude. J Med Ethics Hist Med. $2011 ; 4(5)$.

[15] Latif DA. An assessment of the ethical reasoning of United States pharmacy students: a national survey. Am J Pharm Educ 2004; 68(2): article 30

[16] Ajzen I, Fishbein M. Understanding attitudes and predicting social behavior. Englewood Cliffs, NJ: Prentice-Hall; 1980.

[17] Ajzen I. The theory of planned behavior. Organ Behav Hum Decis Process. 1991; 10: 179-211.

[18] Yildiz G. Professional Ethics in Accounting Profession and an Application Center of Kayseri (article in Turkish with an abstract in English). Erciyes Üniversitesi İktisadi ve İdari Bilimler Fakültesi Dergisi. 2010; 36: 155-178.

[19] Kocabacak S. A Research Related to Problems of Community Pharmacies in Turkey (article in Turkish with an abstract in English). Hacettepe Sağlık İdaresi Dergisi. 2011; 1(2): 95-124.

[20] TITCK (Türkiye İlaç ve Tibbi cihaz Kurumu).

http://www.titck.gov.tr/PortalAdmin/Uploads/UnitPageAttachment/c1cfd8dc10483.pdf (accessed April 26, 2018).

\section{Appendix A}

Case: It was a cold winter's afternoon and business had been slow at the pharmacy all day. In fact, business had been slow ever since the pharmacist took over the pharmacy 3 months ago from the previous owner. It had been difficult to keep finances under control at the time. The bank's notice for late payment instalments had arrived the day before.

It was a relief to be distracted from these worries by an incoming client asking to see the Pharmacist. An elderly woman requested something for her sinuses. She had tried many medications including Paracetamol, Antihistamines and nasal sprays, but nothing seemed to have helped. There were many OTC (over-the counter) products on the shelf with huge bonuses and great promotions. One particularly expensive item looked suitable. Perhaps it might not provide her with much symptom relief, as there was no evidence to prove efficacy, but it would not do much harm either (Chaar, 2009). 